\title{
Uma nova perspectiva para o Livro de Cabeceira
}

\author{
A new perspective for The Pillow Book \\ O LIVRO de Cabeceira. Direção de Peter Greenaway. 1996. DVD \\ (126 min.).
}

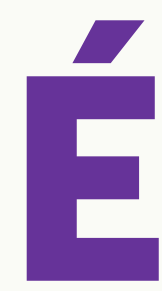

possível aceitar o corpo humano como uma extensão para a vida após a morte e a pele humana como suporte de informação documental quando possuidora de alguma inscrição? A partir da reflexão sobre a temática do presente dossiê da revista, "Dispositivos estatais e construção social dos mortos", relembra-se o filme O Livro de Cabeceira (1996), dirigido e roteirizado por Peter Greenaway. O filme se passa no Japão e em Hong Kong e retrata a paixão da modelo e aspirante a escritora, Nagiko Kiohara, pela literatura e escrita registradas em corpos. Ela cresceu com o costume de ter seu pai pintando seu rosto em seus aniversários com um texto que ressoava como uma benção. Ressalta-se que o processo de pintura corporal que aparece no filme é muito similar ao processo de tatuagem.

Durante muito tempo Nagiko sentia prazer em servir da sua pele como papel e assim possuía amantes que a lembrassem do prazer da caligrafia ao escreverem nela. Após ter seus registros rejeitados por um editor - o mesmo que aceitava os textos de seu pai -, Nagiko confidencia ao seu amante, que também era amante do editor, o desejo de se tornar escritora para honrar o seu pai. Ao ser convencida que deveria ser ela a escritora, ela e o amante tramam um plano em que ela passaria

* Doutoranda em Ciência da Informação pelo Instituto de Ciência da Informação da Universidade Federal da Bahia (Ufba). Arquivista na Universidade Federal da Bahia (Ufba). CV: http://lattes. cnpq.br/3604872097211963 
a escrever na pele dele o que seria um conjunto de 13 livros e ele seria o responsável por levar seus textos até o editor.

No decorrer do filme, Nagiko descobre que seu amante está se relacionando com o editor. Diante disso, passa a usar corpos de outros homens que aceitam utilizar a sua própria pele como suporte de informação para dar continuidade à escrita dos seus livros. Porém, uma fatalidade leva o amante de Nagiko e do editor a óbito. Diante da necessidade de prosseguir a leitura de um dos livros e sabendo que o seu amante foi enterrado com o livro de número 6, o editor providencia a exumação e a extração da pele do cadáver transformando-a em livro. Este se torna seu próprio livro de cabeceira, principalmente por ser a pele de uma pessoa pela qual nutria grande sentimento. A cena da extração da pele e sua preservação apresenta o bisturi cortando a pele do cadáver a fim de garantir os fragmentos textuais para a criação do livro de cabeceira do editor. Para tanto, visualiza-se um procedimento inicial com a pele sendo tratada pelo editor e por sua equipe para se tornar livro.

A morte do amante, porém, não interrompe a escrita dos textos de Nagiko em outros corpos, pois ao saber que o editor retirou a pele de seu amante e a transformou em livro, ela continua a escrever, a fim de recuperar o livro feito com a pele do seu também amante. Fascinado pelo que Nagiko escreve, o editor esboça uma reação a cada corpo que se apresenta a ele. O filme também aponta para a reprodução das mensagens inscritas em pele por meio de registro fotográfico ou por manuscrito com vistas a resguardar a informação materializada no corpo.

Restringindo-se à proposta temática do filme, é possível associar os estudos sobre a morte, os mortos e o morrer a alguns dos temas pesquisados pela Ciência da Informação (Cl), área científica que tem como característica principal a interdisciplinaridade. A colaboração de diversos campos do conhecimento promove enriquecimento para as mais diversas disciplinas (Le Coadic, 1996, p. 22). Na Cl o documento é resultado da união de um suporte mais informação. Isso quer dizer que a informação pode ser registrada em qualquer base material que sirva de inscrição. Diversos foram e são os tipos de suporte, como o papiro, o pergaminho, a pedra, a argila, o papel e, dentre outros, como o próprio corpo humano. Para a documentalista Suzanne Briet (2016, p. 1), o documento é "todo indício, concreto ou simbólico, conservado ou registrado, com a finalidade de representar, reconstituir ou provar um fenômeno físico o intelectual".

Essas explanações basilares são importantes para uma melhor compreensão da extensão do que representa a morte no filme O Livro de Cabeceira. Por meio dele, podemos identificar um relato de que a preservação de parte do morto permitiria ao editor manter ao mesmo tempo um documento e uma memória de pessoa amada. A morte não significa o fim da existência física da pessoa quando seus restos mortais - nesse caso, a pele - servem como recordação física da pessoa morta; ou seja, como documento. Assim, o sentimento de saudades pode ser suprido através de uma lembrança do próprio corpo falecido.

Outra reflexão válida é quando o sentimento de dor e raiva tomam Nagiko ao ver o seu diário - de papel - queimado pelo seu então marido pouco simpático por livros e leituras, após um desentendimento entre casal. No filme, a personagem promete ter um diário para 
escrever sobre tudo, até mesmo sobre todos os seus amantes. Logo, seu diário de papel seria o seu livro de cabeceira. É possível que um diário queimado seja considerado o mesmo que o fim de uma vida, uma vez que se considere o diário como a representação literária da vida de uma pessoa, onde se narram fatos e histórias vividas. Embora não se compare à perda de uma pessoa, a perda do diário poderia ser considerada o fim de um objeto que serviu para registros existenciais que poderiam servir para recordar das histórias com o passar dos tempos. Sabemos que o ato de registrar tem relação também com a capacidade da mente humana em não lembrar de todos os fatos que se deseja; por isso se recorre à escrita como um recurso para memorizar o que se deseja. Cada vez que perdemos um objeto não preservado, nesse caso o documento, podemos nos perguntar se temos a morte da memória. Justamente por isso, concordo com Le Goff (1996, p. 538), para quem o documento é útil e produz efeito, além de ser resultante de uma montagem das sociedades que o produziram e das épocas sucessivas que continuaram a existir, além de ser duradouro e de servir para testemunhar e ensinar.

Semelhantemente, a pele também pode ser um suporte de informação escrita, igualmente como outros suportes, a exemplo do próprio papel, que tem poder de agir na sociedade. Nesse caso, os registros corporais serviram de recurso para a jovem Nagiko alcançar o editor ao ponto de deixá-lo fascinado com o que foi escrito e ansioso pelo conteúdo dos livros seguintes. Talvez, por isso, aceitar o documento apenas como transmissor exclusivo de informação é reduzir a sua ação entre sujeitos, pois o documento não apenas informa algo a alguém, mas também serve de prova e testemunho, garante direitos, promove conhecimento e auxilia na tomada de decisões. Decerto, é esperado que qualquer informação gere ação quando documentada. Nesse sentido, conforme afirma Frohmann (2006, p. 21):

"documento" nomeia a materialidade da informação, e se a materiali-
dade é importante para o entendimento dos aspectos públicos e so-
ciais da informação, então os estudos da documentação tornam-se
importantes para os estudos da informação. A documentação se torna
o meio de materialização da informação. Estudar a documentação é
estudar as conseqüências e os efeitos da materialidade da informação.

A materialização de uma informação pode modificar as estruturas sociais e mentais de uma dada cultura ou sociedade, pois sua circulação enquanto documento promove diversas ações e comportamentos a partir do que está escrito. Um exemplo prático são as informações contidas em um testamento, pois os dados ali registrados, geralmente, tendem a definir a vida das pessoas contempladas. Desse modo, a materialização da informação registrada na pele dos personagens movimenta o filme, pois recebendo os livros por etapa, observa-se o comportamento fascinado do editor a cada corpo que chega com a pele inscrita e sua surpresa ao perceber que o texto se encontrava escondido em pequenas partes do corpo que pensara inicialmente não conter informação.

Tais questões refletem as emoções vivenciadas pelos personagens em relação ao texto escrito sobre a pele. Assim como a preocupação em garantir uma pele lisa e macia para apor a informação contida nas mensagens que serão transmitidas por meio dos corpos que 
dinamizam os personagens do filme. Como constatam Kobashi e Tálamo (2003), "a informação é, de fato, um dos elementos básicos para inteligibilidade dos processos, sejam eles naturais ou culturais". Desse modo, no filme, a presença e a ausência da informação aguçam os sentidos quando a ira do editor é assistida ao pensar que todo um livro estava perdido por achar que a chuva teria desmanchado um texto e se surpreender com o texto inscrito na língua.

Em sua teoria, Briet (2016) relata que todo documento produzido a partir de um primeiro é considerado secundário. Ao exemplificar que uma espécie rara de antílope catalogado e colocado em um zoológico também é documento, todo e qualquer documento produzido a partir dele - seja um artigo de jornal, um registro visual, um boletim ou uma nota técnica - é um documento secundário. Relacionando com o filme, isso corrobora a ideia da impossibilidade imediata de preservar o "documento"/corpo em seu estado natural na ausência da morte. $O$ que se explica por que no filme os registros são realizados com tinta não permanente ou lavável; ou seja, se não se fizer um segundo registro por fotografia, vídeo, ou cópia manuscrita, a informação fica irrecuperável quando limpa, deixando a pele novamente com um espaço para novas informações. Além disso, a extração da pele com registros informacionais não seria aceitável em uma pessoa com vida. Desse modo, o documento primário se perde a partir do momento em que o registro é apagado do corpo. Qualquer outra tentativa de escrita do mesmo texto, é uma cópia do que foi apagado. Mesmo mantendo o suporte com forma e formato singular, pode ser difícil para o mesmo autor manter os mesmos traços e tamanhos do texto ou imagem anterior.

É importante não confrontar o documento em pele apenas como memória póstuma. Após a morte do sujeito, a pele preservada em sua totalidade ou fragmento apresenta informação e/ou fatos que contextualizam um período da humanidade, vivenciadas ou não, mas representadas por aquele corpo. Exemplo disso pode ser o acervo do Instituto Nacional de Medicina Legal e Ciências Forenses I.P. (INMLCF.IP), que reúne tatuagens dos presos portugueses do início do século XX que remontam à antiga Lisboa. ${ }^{1}$ Outro exemplo são as cabeças tatuadas dos guerreiros das tribos Maoris que se encontram no museu nacional Te Papa Tongarewa, na Nova Zelândia e, ainda, 134 corpos mumificados com tatuagens ou pinturas corporais localizadas no complexo funerário Cerro Colorado no Peru (Luna, Enciso Y Majchrzak, 2019). Compreende-se, pois, que as "investigações sobre a materialização da informação através da documentação podem identificar os campos de força institucional, tecnológico, político, econômico e cultural - que configuram características públicas e sociais da informação" (Frohmann, 2006, p. 33). A pele enquanto documento possui em si informações que expressam situações vividas nas mais diversas esferas sociais. São relatos corporificados relacionados a momentos determinantes de um povo ou grupo e que podem agir diretamente na geração presente ou futura em função do conteúdo expresso.

Pensar na preservação do corpo ou parte dele após a morte é refletir sobre uma manifestação corporal que pode servir para a identificação humana. Tais questões também

O MAIS PROFUNDO É A PELE. Coleção de tatuagens 1910-40 Instituto Nacional de Medicina Legal e Ciências Forenses. MUDE, 2017. Disponivel em: <http://www.mude.pt/exposicoes/o-mais-profundo-e-a-pele-colecaode-tatuagens-191040-instituto-nacional-de-medicina-legal-e-ciencias-forenses_77.html>. Acesso em: 14 dez. 2020. 
nos permitem refletir sobre a legislação que permita a extração da pele, para destino além do ensino e da investigação científica. Ciente da existência do acervo de peles tatuadas do INMLCF.IP constatei que a legislação portuguesa prevê no Decreto-Lei 11/1998 a dissecação de cadáveres ou extração de tecidos para fins de ensino e de investigação científica e que as peças anatômicas possam ser destinadas ao museu do serviço médico-legal. ${ }^{2}$

No Brasil esse ainda é um campo a ser explorado. Por isso, a mensagem maior que se extrai do filme é acerca da possibilidade do estudo das práticas de registro de preservação da pele humana após a morte, que possam ser resguardadas após a sua existência terrena, a fim de promover maior interlocução entre as gerações. Sendo a morte a única certeza da vida, cabe ao Estado prover uma legislação acerca da preservação do corpo ou de parte dele após morte, talvez, garantindo dispositivos legais, como o de doação de órgãos, para que o sujeito em vida, ou um familiar, possa destinar a sua pele quando possuidora de um registro de informação. A legislação existe para regular a sociedade em relação às suas ações. A falta de uma política para executar determinada ação, como a extração da pele de alguém visando salvaguardar uma lembrança ou memória, impede esse procedimento.

Preservar e conservar o corpo ou parte dele pode ter relevância histórica e social porque pode contar a história de povos e nações, a exemplo das pinturas indígenas, das pinturas corporais dos povos papuas, das tatuagens que numeravam e identificavam os judeus, das escarificações sofridas pelos negros escravizados, dentre outras. As práticas sociais da tatuagem são construídas em vida, mas muitas não são mantidas pós-morte, com exceção de alguns museus que possuem em seus acervos corpos mumificados, fragmentos de pele tatuada que se encontram em museus - como o Museu de Patologia da Universidade de Tóquio, no Japão, o INMLCF.IP em Portugal e a Welcome Collection no Museu da Ciência de Londres na Inglaterra.

Retomando o tema do dossiê desse número 10 da Revista M., podemos argumentar que a construção social de mortos é possível através de corpos que possuam inscrições em pele, que traduzam um período histórico, demonstrem fatos, sirvam de evidências e comprovações sociais de um povo. São características que também servem para individualizar e identificar um corpo e para representar um grupo. Por isso, é possível considerar que os corpos se tornam documentos por conterem informação materializadas pelo homem, tornando-se um acontecimento narrado e reproduzido em texto e imagem que contextualize um evento, adornos ou modificações corporais para expressar um costume ou uma cultura. Tais argumentos me levam a cogitar que aceitar o fim de um determinado corpo pode ser visto como um ato de não prezar pela memória histórica, social e cultural.

Preservar e conservar a pele após a morte confirma o que Briet (2016, p. 4) defendia. Para ela, as pessoas se satisfazem com outros tipos de documentos e a pesquisa científica pode ser realizada com outras unidades documentárias. É urgente ampliar o debate legal sobre a extração de pele humana para fins pessoais e culturais. Pensar em extração de pele implica em novos estudos por parte das ciências jurídicas e da medicina. No entanto, um trabalho multidisciplinar, em conjunto com profissionais de diversas áreas - como designers,

PORTUGAL. Decreto-Lei no 11, de 24 de janeiro de 1998. Diário da República - I SÉRIE- A, no 20, p. $274,1998$. 
antropólogos, historiadores, juristas, médicos, bibliotecários, arquivistas, museólogos, dentre outros -, poderá responder questões, tais como: é necessário preservar a pele humana? Quais aspectos legais devem ser observados? Qual cuidado se deve ter antes de morrer? A extração de um registro em pele pode ser objeto de doação para um ente querido? Como preservar a pele pós-morte? É possível ser emoldurada? Será enriquecedor agregar mais áreas do conhecimento como história, antropologia, arquivologia, museologia e outras, para desmistificar temas que giram em torno da morte do corpo físico.

Quanto mais o assunto morte for observado com naturalidade nas mais diversas áreas do saber, e também em momentos de lazer, como em um filme, outros temas afins poderão ser abordados sem temor e preconceito. Por isso, assistir O Livro de Cabeceira aprofunda olhares e sentimentos ainda controversos quando pensamos em vida e morte.

\section{Referências Bibliográficas}

BRIET, Suzanne. O que é a documentação? Tradução de Maria de Nazareth Rocha Furtado. Brasília, DF: Briquet de Lemos, 2016. 106 p.

FROHMANN, Bernd. O caráter social, material e público da informação na contemporaneidade. In: ENCONTRO NACIONAL DE PESQUISA E PÓS-GRADUAÇÃO EM CIÊNCIA DA INFORMAÇÃO (ENANCIB), 7., 2006, Marília. Anais [...]. Marília: [s. n.], 2006. Disponível em: <http://hdl.handle. net/20.500.11959/brapci/5679>. Acesso em: 20 mar. 2020.

KOBASHI, Nair Yumiko; TÁLAMO, Maria de Fátima Gonçalves Moreira. Informação: fenômeno e objeto de estudo da sociedade contemporânea. Transinformação, Campinas, v. 15, (Edição Especial), p. 7-21, set./dez., 2003. http://doi.org/10.1590/s0103-37862003000500001. Disponível em: <http://www.scielo.br/scielo.php? script=sci_arttext\&pid=S0103-37862003000500001\&lng=en\&nrm=iso>. Acesso em: 20 mar. 2020

LE COADIC, Yves François. A Ciência da Informação. Tradução de Maria Yêda F. S. de Filgueiras Gomes. Brasília, DF: Briquet de Lemos, 1996. 124 p.

LE GOFF, Jacques. História e memória. Tradução de Irene Ferreira, Bernardo Leitão, Suzana Ferreira Borges Campinas: Editora UNICAMP, 1996. 538 p.

LUNA, Pieter Dennis Van Dalen; ENCISO, Alfredo Altamirano; MAJCHRZAK, Łukasz. Marcas para la vida, señales para la muerte Los cuerpos tatuados de la cultura Chancay en Cerro Colorado, Huacho, Perú. Revista M. Estudos sobre a morte, os mortos e o morrer, Rio de Janeiro, v. 3, n. 6, p. 344-377, mar. 2019. Disponível em: <http://seer.unirio.br/index.php/revistam/article/ view/9045>. Acesso em: 18 dez. 2020.

O LIVRO de Cabeceira. Direção e roteiro: Peter Greenaway. Produção: Kees Kasander. [S. l.]: Centurion; Kasander \& Wigman Productions; Woodline Films Ltd., 1996. 1 DVD (126 min), son., color., $35 \mathrm{~mm}$.

Enviado em: 30 de março de 2020

Aprovado em: 17 de novembro de 2020 